\title{
Detection of Leishmania Parasite in Sero-Positive Individuals in Tabark Allah Village, Esatern Sudan.
}

\author{
Mohammed A. E. ${ }^{1}$ and Abdelsafi A. G. ${ }^{2}$ \\ ${ }^{I}$ Department of Public Health, College of Health Sciences at Aleith, Umm Al-qurq University, Saudi Arabia \\ ${ }^{2}$ Department of Public Health, College of Health Sciences at Aleith, Umm Al-qurq University, Saudi Arabia
}

\begin{abstract}
A study was conducted to detect Leishmania donovani in sero-positive individuals and to describe the patients by age and sex in Tabark Allah village, eastern Sudan. Sixty four individuals with positive direct agglutination test were examined by lymph node aspiration test using Giemsa's stain. Amastigotes of Leisshmania parasite were detected in 49(76.6\%) of the study group. Majority of true positives were children less than fifteen years old. Males were more frequent than females. Direct Agglutination Test is considered as an assumptive test and it is suitable to be used in epidemiological surveys.
\end{abstract}

Key Words: Agglutination, Aspiration, donovani, Lymph, Leishmania, Node,

\section{Introduction}

Leishmaniasis is a group of protozoan diseases caused by certain species of genus leishmania and transimitted by 30 species of sand fly [1]. It is a common disease in less developed countries with approximately 500,000 new cases each year [2], more than $90 \%$ of which are found in the Indian subcontinent, Sudan and Brazil [3].

In Sudan the causative agents are $L$. donovani and $L$. Infantum and the principal vector is phlebotomus orientalis while the animal reservoirs are dog, monkey and fox [4]. Visceral leishmaniasis or kala-azar is of major importance in Sudan leading to thousands of deaths [5]. Since 1900s visceral leishmaniasis has been considered one of the important health problems in Sudan, especially in eastern and central regions [4].

The direct agglutination test (DAT) has proved to be a very important sero-diagnosis tool for the diagnosis of visceral leishmaniasis [6]. Diagnosis is based on demonstration of Leishmania donovani bodies in smears obtained from bone marrow, lymph nodes, spleen, liver and skin snap smears. Looking for parasites in the spleen and liver is one of the most accurate methods available. About Ninty percent of the active cases show parasites in splenic and liver aspirates [7]. Lymph node aspiration test could detect $80 \%$ of cases [4].

Although the disease infects all age groups, it is more frequent in children younger than 15 years [8]. It has been reported that males were more affected than females due to behavioural characteristics [9].

Study area

\section{Materials And Methods}

The study was carried out in Tabarkallah village, eastern Sudan. It is located at approximately $120 \mathrm{~km}$ south Gedaref town. The area is one of leishmaniasis endemic zones in Sudan and witnessed several outbreaks in the previous years.

\section{Lymph node aspiration Test}

Lymph node aspiration test (LNAT) was applied on sixty four individuals (37 males and 27 females). They were positive Direct Agglutination Test (DAT) in a survey conducted in the village before our study. Smear samples were collected from inguinal lymph nodes, stained with Giemsa's stain and examine under the microscope for the presence of amastigotes.

\section{Results}

The findings showed that $49(76.6 \%)$ of sero-positive individuals were positives when they were subjected to lymph nodes aspiration test (LNAT) as illustrated in table 1. Age distribution of serpositive individuals according to the result of lymph node aspiration test showed that ninety percent $(90 \%)$ of children $(<15)$ were positives, followed by age group 15-24years, $(p=0.054)$.

Breakdown of the data by sex showed that the percentage of infection in males was (78.4\%) compared to $74.1 \%$ among females using lymph node aspiration test (LNAT), $(O R=1.2688,95 \% \mathrm{CI}: 0.3964-4.0613)$ as presented in table 3. 
Table (1): The yield of lymph nodes aspiration test (LNAT) for visceral leishmaniasis, in Tabark Allah village, Gedaref state 2010. $(n=64)$.

\begin{tabular}{|l|l|l|}
\hline LNAT & No & $\%$ \\
\hline positive & 49 & $76.6 \%$ \\
\hline negative & 15 & $23.4 \%$ \\
\hline Total & 64 & $100 \%$ \\
\hline
\end{tabular}

Table (2): Age distribution of study group according to the result of lymph node aspiration test in Tabark Allah village, Gedaref state 2010. $(n=64)$

\begin{tabular}{|c|c|c|c|c|c|c|}
\hline \multirow[b]{3}{*}{ Age } & \multicolumn{4}{|c|}{ Lymph nodes aspiration test } & & \\
\hline & \multicolumn{2}{|c|}{ positive } & \multicolumn{2}{|c|}{ negative } & \multicolumn{2}{|c|}{ Total } \\
\hline & No & $\%$ & No & $\%$ & No & $\%$ \\
\hline$<15$ & 27 & $90 \%$ & 3 & $10 \%$ & 30 & $46.9 \%$ \\
\hline $15-24$ & 12 & $75 \%$ & 4 & $25 \%$ & 16 & $25 \%$ \\
\hline $25-34$ & 3 & $50 \%$ & 3 & $50 \%$ & 6 & $9.4 \%$ \\
\hline $35-65$ & 7 & $58.3 \%$ & 5 & $41.7 \%$ & 12 & $18.7 \%$ \\
\hline Total & 49 & $76.6 \%$ & 15 & $23.4 \%$ & 64 & $100 \%$ \\
\hline
\end{tabular}

$X^{2}=7.622$

$P=0.054$

Table (3): Sex distribution of of study group according to the result of lymph node aspiration test in Tabark Allah village, Gedaref state 2010. $(n=64)$

\begin{tabular}{|c|c|c|c|c|c|c|}
\hline \multirow[b]{3}{*}{ Sex } & \multicolumn{4}{|c|}{ Lymph nodes aspiration test } & & \\
\hline & \multicolumn{2}{|c|}{ positive } & \multicolumn{2}{|c|}{ negative } & \multicolumn{2}{|c|}{ Total } \\
\hline & No & $\%$ & No & $\%$ & No & $\%$ \\
\hline Female & 20 & $74.1 \%$ & 7 & $25.9 \%$ & 27 & $42.2 \%$ \\
\hline Total & 49 & $76.6 \%$ & 15 & $23.4 \%$ & 64 & $100 \%$ \\
\hline
\end{tabular}

Odds ratio $(O R)=1.2688 \quad 95 \%$ confidence interval $(C I)=0.3964-$

4.0613

\section{Discussion}

Lymph node aspiration is by far the easiest and most convenient method and is recommended for use in hospitals and in the field. The technique was introduced in Sudan in 1940 by Kirk and Sati.

About 64 individuals with DAT positives were considered as suspected cases. Approximately, 76.6\% of them were confirmed with lymph node aspiration test. The yield of lymph node aspiration test (LNAT) for visceral leishmaniasis that was achieved by LNAT is closed to standard as the test, usually; detect $80 \%$ of cases [4].

There was statistical significant association between visceral leishmaniasis and age of individual $(p=05)$. The children were more affected than adults. This result agrees with findings of several studies which they mentioned that the disease is more frequent in children. In Um-Salala village, Sudan, Zijlstra and Elhassan (2001) found that $50 \%$ of infected individuals were in age group $5-15$. Also the World Health Organization reported in 2007 that children under the age of 15 years are the most severely affected age group. These supported also by a study conducted In Venezuela, 80.6\% of infected persons were younger than 15 years [8].

The high distribution of visceral leishmaniasis among certain ages lead to a question whether this is due to immunological factors or their activities and habits which render them to be exposed to infection more than others. However the vector of the disease is present indoors and outdoors and its activity during the daytime and at night too.

Visceral leishmaniasis affects both sexes, but a higher frequency of the disease in males has been found in many studies [10] [11]. In the present study more males were positives when we used lymph node aspiration. Many previous studies explained that the reason for a higher rate of visceral leishmaniasis in males has been attributed to the intensive activity of males outdoor in agriculture and forests, and they have been exposed to sand fly biting.

\section{Conculosion}

Lymph node aspiration test could detect leishmania donovani in ser-positive individuals. The direct agglutination test is considered as initial test to sort suspected cases of visceral leishmaniasis and is suitable for epidemiological survey. 


\section{Acknowledgements}

Thanks to administration of Kala azar Hospital in Tabark Allah for giving us the opportunity to work in the Hospital Laboratory. Also our thanks to Gedaref state Minstry of Health for the consent to conduct the research in the village.

\section{References}

[1] Joshi S., Bajracharya B. L., and Baral M. R. (2006). Kala-azar (visceral leishmaniasis). Kathmandu University Medical Journal 4(2): 232-234

[2] Guerin P. J., Olliaro P., Sundar S., Boelaert M., Croft S. L., Desjeux P., Wasunna M. K., Bryceson A. D. (2002). Visceral leishmaniasis : current status of control, diagnosis and treatment, and a proposed research and development agenda . Lancet Infect; 2(8): $494-501$

[3] Diaeldin A E, Judith S, Anna B, Valerie O, Maha E O, Abdelrafie M M, Stephen J C, Richard W A, Madeleine C T. (2003). Risk mapping of visceral leishmaniasis: The role of local variation in rainfall and altitude on the presence and incidence of kala-azar in eastern Sudan. AMJ Trop Med Hyg. 68(1): 10-17.

[4] Zijlstra E. E. and Elhassan A. M. (2001). Leishmaniasis in Sudan: visceral leishmaniasis. Trans R Soc Trop Med Hyg 95 suppl 1: s27-58.

[5] Magill A. J. (1995). Epidemiology of leishmaniasis. Dermatol Clin, 13(3): 505-23.

[6] Eduardo S. S., Gerard J. S., Celia M. F., Reginaldo P. B., Raquel S. P., and Henk D. F. (2005). Application of Direct Agglutination Test (DAT) and Fast Agglutination Screening Test (FAST) for sero-diagnosis of visceral leishmaniasis in endemic area of Minas Gerais, Brazil. Kinetoplastid Biology and Disease 4(4): doi: 10.1186/1475-9292-4-4.

[7] Muhammad U., Sheraz J. K., Syed M., Fazal R. and Syed H. S. (2004). Visceral Leishmaniasis (Kala Azar): Presentation, Diagnosis And Response To Therapy (An Experience Of Ten Cases In Adults). Gomal Journal of Medical Sciences. $2(1) .9$-12.

[8] Olga Z., Marian U., Rafael B., Vestalia R., Marta C., Emilia N., Doris B., and Jacinto C. (2003). Epidemiological aspects of human and canine visceral leishmaniasis in Venezuela. Rev Panam Salud Publica/Pan Am J Public Health 13(4): 239-45.

[9] Sarker C. B., Chowdhury K. S., Siddiqui N. I., Jamal M. F., Rahman S., Momen A., Dhar D. K., and Alam K. S. (2003). Clinical profile of kala-azar in adults: as seen in Mymensingh MedicalCollege Hospital, Mymensingh, Bangladesh. Mymensingh Med $J$ 12(1): 41-44.

[10] Pedrosa C. M, and Rocha E. M. (2004). Clinical and epidemiological aspects of visceral leishmaniasis in children up to 15 years of age in Alagoas, Brasil. Rev Soc Bras Med Trop 37(4): 300-304.

[11] Khlabus K. h. (2007). Clinical and epidemiological features of kala-azar in Thi-Qar Governorate. MJBU 25(1): 51-54 